\title{
Regulation of Orthogonal Functions in a Dual Catalyst System. Subservient Role of a Non-chiral Lewis Acid in an Asymmetric Catalytic Heteroatom Diels-Alder Reaction
}

\author{
Cory A. Newman ${ }^{\dagger}$, Jon C. Antilla ${ }^{\dagger}$, Pei Chen ${ }^{\dagger}$, Alexander V. Predeus ${ }^{\dagger}$, Lee Fielding ${ }^{\ddagger}$, and \\ William D. Wulff ${ }^{\star},+$ \\ $\dagger$ Department of Chemistry, Michigan State University, East Lansing, Michigan 48824
}

†Organon Laboratories Ltd., Newhouse, Lanarkshire, Scotland, ML1 5SH

\section{Abstract}

A catalytic asymmetric heteroatom Diels-Alder reaction of unactivated imines with Danishefsky's diene is described which gives high asymmetric induction for N-benzhydryl imines derived from a variety of aldehydes. The catalyst is derived from $\mathrm{B}(\mathrm{OPh})_{3}$ and the VAPOL ligand and gives good induction but the reaction stalls and does not give high conversion $(\sim 50 \%)$. It was found that in the presence of the both the chiral catalyst and excess amounts of $\mathrm{B}(\mathrm{OPh})_{3}$ the reaction proceeds to completion and gives high yields of the dihydropiperidinone product. Despite the presence of large quantities of the non-chiral Lewis acid $\mathrm{B}(\mathrm{OPh})_{3}$ the asymmetric induction of the product remains constant $\left(90 \%\right.$ ee) as the amount of $\mathrm{B}(\mathrm{OPh})_{3}$ is steadily increased and does not drop off until the ratio of $\mathrm{B}(\mathrm{OPh})_{3}$ to VAPOL is 100:1 (82\% ee). These observations are interpreted as involving highly separated and different activities for the chiral and non-chiral Lewis acids present in the reaction. Specifically, the excess $\mathrm{B}(\mathrm{OPh})_{3}$ serves to bind to the product and release the chiral catalyst to turnover more starting material. The $\mathrm{B}(\mathrm{OPh})_{3}$ does not compete in turning over of the starting material and a series of binding studies reveals that this likely due to a combination of two factors. The binding studies reveals that the chiral catalyst binds to the starting imine seven times more strongly than does $\mathrm{B}(\mathrm{OPh})_{3}$. However, in order to explain the constant asymmetric induction observed despite the addition of increasing amounts of $\mathrm{B}(\mathrm{OPh})_{3}$ the rate of the reaction of the imine complexed with the chiral catalyst must be at least 10 times faster than the reaction of the imine complexed with $\mathrm{B}$ $(\mathrm{OPh})_{3}$. Finally, a catalyst generated from BINOL and $\mathrm{B}(\mathrm{OPh})_{3}$ does not show this phenomenon.

Attempts to develop chiral catalysts for asymmetric reactions of imines must confront the problem that the product is more basic than the starting imine thus leading to difficulty in turnover. ${ }^{1}$ A scenario in which both turnover and asymmetric induction could be realized would involve two catalysts, one chiral and one non-chiral (eq. 1). If the non-chiral catalyst was in excess then it could free up the chiral catalyst to turn over the reaction. Asymmetric induction could be achieved if the chiral catalyst has a larger binding constant than the nonchiral catalyst for imine $\mathbf{1}$, or if the chiral catalyst promotes the reaction at a sufficiently greater rate that it can overcome its molar disadvantage, or if both were to pertain. We report here the discovery of such a two catalyst system where at least 20 turnovers can be achieved in a heteroatom Diels-Alder reaction with no loss of induction. This type of dual-Lewis acid catalyst system with orthogonal functions is to our knowledge unprecedented. 2,3

E-mail: wulff@ chemistry.msu.edu. 


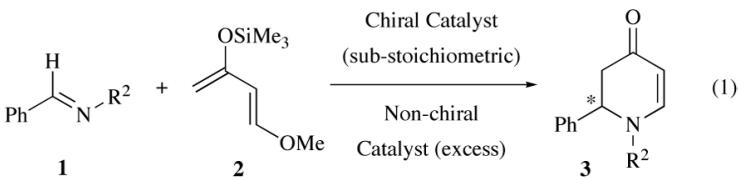

The first report of a heteroatom Diels-Alder reaction of an imine catalyzed by a chiral Lewis acid involved a catalyst prepared from $(R)$-BINOL and triphenylborate. ${ }^{4,5}$ With a stoichiometric amount of catalyst $\mathbf{6}$ the reaction produces the Diels-Alder adduct 3a in $75 \%$ yield and $82 \%$ ee (Table 1, entry 1). ${ }^{4 \mathrm{a}}$ However, if $10 \mathrm{~mol} \%$ of the catalyst is used less than $5 \%$ yield was observed. ${ }^{4 \mathrm{~b}}$ Interestingly, when $10 \mathrm{~mol} \%$ of $(R)$-BINOL and $100 \mathrm{~mol} \% \mathrm{~B}$ $(\mathrm{OPh})_{3}$ is used the reaction proceeds but with a reduced asymmetric induction as might be expected as a result of a background reaction catalyzed by the excess $\mathrm{B}(\mathrm{OPh})_{3}$.

Based on the results from the BINOL catalyst 6 (Table 1, entry 2), it was not unexpected to find that the same reaction with a catalyst prepared from $10 \mathrm{~mol} \%(S)-\mathrm{VAPOL}^{6}$ and $100 \mathrm{~mol}$ $\%$ of $\mathrm{B}(\mathrm{OPh})_{3}$ gave a $50 \%$ yield of 3a with $36 \%$ ee (Table 2 , entry 1$) .{ }^{7}$ However, it was very surprising to find that the same reaction with imine $\mathbf{1 b}(\mathrm{R}=\mathrm{Ph})$ gave $3 \mathbf{b}$ in $94 \%$ yield and $90 \%$ ee (Table 2, entry 2). It was further found that the $\%$ ee of the product does not decrease until a 40:1 ratio of $\mathrm{B}(\mathrm{OPh})_{3}$ to (S)-VAPOL was used (entry 5). The reaction of a catalyst prepared from $(R)$-BINOL using the procedure for the preparation of catalyst $\mathbf{8}$ gave $\mathbf{3 b}$ with low asymmetric induction and in a yield that is near that of the background reaction (entries 7 and 9).

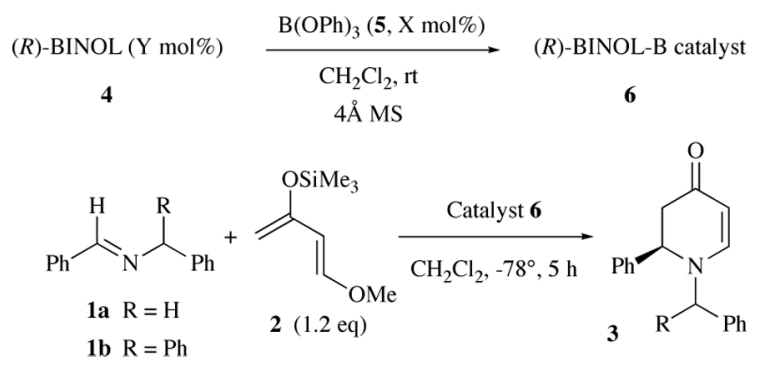

The results from a series of experiments to examine the effect of varying amounts of excess B $(\mathrm{OPh})_{3}$ with $5 \mathrm{~mol} \%(S)$-VAPOL proved to be quite informative (Chart 1$)$. The $\%$ ee for $\mathbf{3 b}$ rose to $90 \%$ with only $15 \mathrm{~mol} \% \mathrm{~B}(\mathrm{OPh})_{3}$ and did not drop until $500 \mathrm{~mol} \%$ was added $(82 \%$ ee). The yield of the reaction continuously rose with each addition of more $\mathrm{B}(\mathrm{OPh})_{3}$ from 58 $\%$ at $15 \mathrm{~mol} \%$ to $95 \%$ at $150 \mathrm{~mol} \%$. Since the \% ee of $\mathbf{3 b}$ remained constant over the same range, the increase in yield can't be due to a background reaction with $\mathrm{B}(\mathrm{OPh})_{3}$.

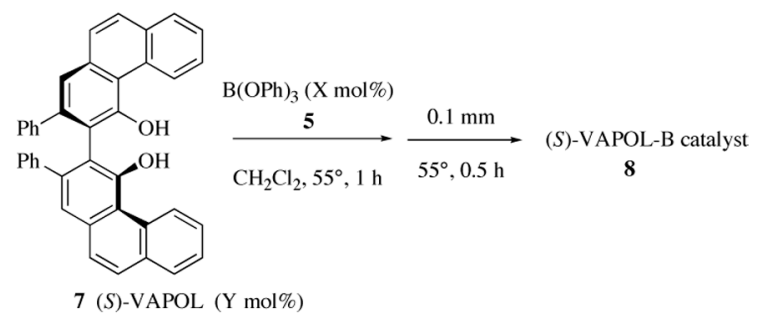

One explanation consistent with these results is that the increasing amounts of $\mathrm{B}(\mathrm{OPh})_{3}$ can better compete with the chiral catalyst in binding to the product and thus liberate the sequestered chiral Lewis acid. The question is why doesn't the increasing amounts of $\mathrm{B}(\mathrm{OPh})_{3}$ lead to a background reaction and loss of significant asymmetric induction. These observations could 
be explained simply by an increase in Lewis acidity that would be expected if catalyst $\mathbf{8}$ were a cyclic borate ester. ${ }^{8}$ The question is whether the increase in the Lewis acidity of the VAPOL$\mathrm{B}(\mathrm{OPh})_{3}$ derived catalyst 8 would be sufficient to account for the results in Chart 1. In an attempt to answer this question a study was undertaken to measure the binding constants of the catalyst 8 and $\mathrm{B}(\mathrm{OPh})_{3}$ with both the imine $\mathbf{1 b}$ and product $3 \mathbf{b}$. The binding constants were determined by ${ }^{1} \mathrm{H}$ NMR titration experiments with increasing amounts of either catalyst 8 or $\mathrm{B}(\mathrm{OPh})_{3}$ added to either imine $\mathbf{1 b}$ or product $\mathbf{3 b}$. Monitoring the chemically induced shift of the benzhydryl proton in $\mathbf{1 b}$ and the vinyl proton in $\mathbf{3 b}$ adjacent to the carbonyl, the binding constant was determined for $\mathrm{B}(\mathrm{OPh})_{3}$ to be $2.7 \pm 0.4 \mathrm{M}^{-1}$ with $\mathbf{3 b}$ and $0.32 \pm 0.12 \mathrm{M}^{-1}$ with $\mathbf{1 b}$ and for catalyst 8 to be $4.9 \pm 0.8 \mathrm{M}^{-1}$ with $3 \mathbf{b}$ and $2.1 \pm 0.4 \mathrm{M}^{-1}$ with $\mathbf{1 b}$. Thus, the VAPOL catalyst 8 binds to the imine $\mathbf{1 b} 7$ times stronger than $\mathrm{B}(\mathrm{OPh})_{3}$ while it binds to the product $\mathbf{3 b}$ only about twice as strongly. While the nature of the binding of catalyst $\mathbf{8}$ to imine $\mathbf{1 b}$ is not known, these binding constants alone are not sufficient to account for the data shown in Chart 1 . Therefore, these data must be a result of a combination of the increased binding of the chiral catalyst and an increased rate of the reaction of imine $\mathbf{1 b}$ with the chiral catalyst over that of the non-chiral catalyst. To explain these data, the difference in rate must be at least a factor of 100 .

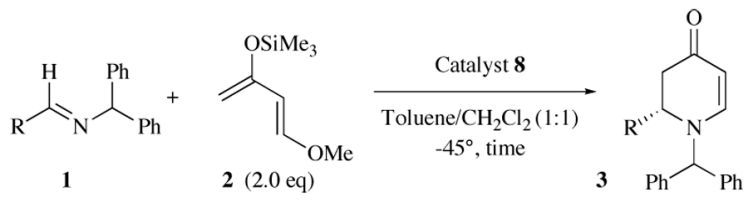

This catalyst system was found to have utility in providing turnover for the heteroatom DielsAlder reaction with a variety of other benzhydryl imines (Table 3 ). The reaction was fairly general for imines prepared from aromatic aldehydes. $\alpha, \beta$-Unsaturated imines appear to need a substituent in the $\alpha$-position as high selectivity was observed for the imine of cyclohexene carboxaldehyde but not for cinnamyl aldehyde. Imines from unbranched aliphatic aldehydes gave racemic product, those from $\alpha$-branched aliphatic aldehydes gave high ee and those from $\alpha, \alpha$-disubstituted aldehydes were unreactive.

While the data can be explain by the scenario outlined in Eq 1, it is possible that that an ionic catalyst is involved that results from abstraction of a phenoxy group by the excess triphenylborate. ${ }^{9}$ Further studies to shed light on the workings of this catalyst system are ongoing.

\section{Supplementary Material}

Refer to Web version on PubMed Central for supplementary material.

\section{Acknowledgement}

This work was supported by a grant from the NIH (NIGMS 63019).

\section{References}

1. (a) Kobayashi S, Ishitani H. Chem. Rev 1999;99:1069-1094. [PubMed: 11749440] (b) Rowland GB, Rowland EB, Zhang Q, Antilla JC. Current Organic Chemistry 2006;10:981-1005.

2. $\mathrm{Yu}$ and coworkers have noted that $\mathrm{B}(\mathrm{OMe})_{3}$ will accelerate the catalytic asymmetric allylation of aldehydes with allyl stannanes with a BINOL-titanium complex. The mechanism of this process is not known but may involve an alkoxide exchange between titanium and boron on the product. Yu C-M, Choi H-S, Yoon S-K, Jung W-H. Synlett 1997:889-890. 
3. A recent review has cited six different classes of additives and cocatalysts but none include the situation in Eq 1 where increasing amounts of a nonchiral Lewis acid results in increased yields without effecting the induction of a chiral Lewis acid: Vogl EM, Gröger H, Shibasaki M. Angew. Chem. Int. Ed 1999;38:1571-1577.

4. (a) Hattori K, Yamamoto H. Tetrahedron 1993;49:1749-1760. (b) Cros JP, Perez-Fuertes Y, Thatcher MJ, Arimori S, Bull SD, James TD. Tetrahedron: Asymmetry 2003;14:1965-1968. (c) Furman B, Dziedzic M, Kaminska A. Polish J. Chem 2005;79:1919-1927.

5. For catalytic systems that turnover, see: (a) Kobayashi S, Komiyama S, Ishitani H. Ang. Chem. Int. Ed 1998;37:979-981. (b) Yao S, Johannsen M, Hazell RG, Jorgensen KA. Angew. Chem. Int. Ed 1998;37:3121-3124. (c) Bromidge S, Wilson P, Whiting A. Tetrahedron Lett 1998;39:8905-8908. (d) Josephsohn NS, Snapper ML, Hoveyda AH. J. Am. Chem. Soc 2003;125:4018-4019. [PubMed: 12670201] (e) Manchen GO, Arrayas RG, Carretero JC. J. Am. Chem. Soc 2004;126:456-457. [PubMed: 14719929] (f) Sunden H, Ibraqhem I, Eriksson L, Cordova A. Angew. Chem. Int. Ed 2005:4877-4880. (g) Yamashita Y, Mizuki Y, Kobayashi S. Tetrahedron Lett 2005;46:1803-1806. (h) Itoh J, Fuchibe K, Akiyama T. Angew. Chem. Int. Ed 2006;45:4796-4798. (i) Akiyama T, Tamura Y, Itoh J, Morita H, Fuchibe K. Synlett 2006:141-143.

6. (a) Bao J, Wulff WD, Rheingold AL. J. Am. Chem. Soc 1993;115:3814-3815. (b) Bao J, Wulff WD, Dominy JB, Fumo MJ, Grand EB, Rob AC, Whitcomb MC, Yeung S-M, Ostrander RL, Rheingold AL. J. Am. Chem. Soc 1996;118:3392-3405.

7. For other applications of the VAPOL ligand, see: Patwardhan AP, Pulgam VR, Zhang Y, Wulff WD. Angew. Chem. Int. Ed 2005;44:6169-6172.references therein.

8. James TD, Shinkai S. Top. Curr. Chem 2002;218:159-200.

9. We thank a referee for this suggestion. 


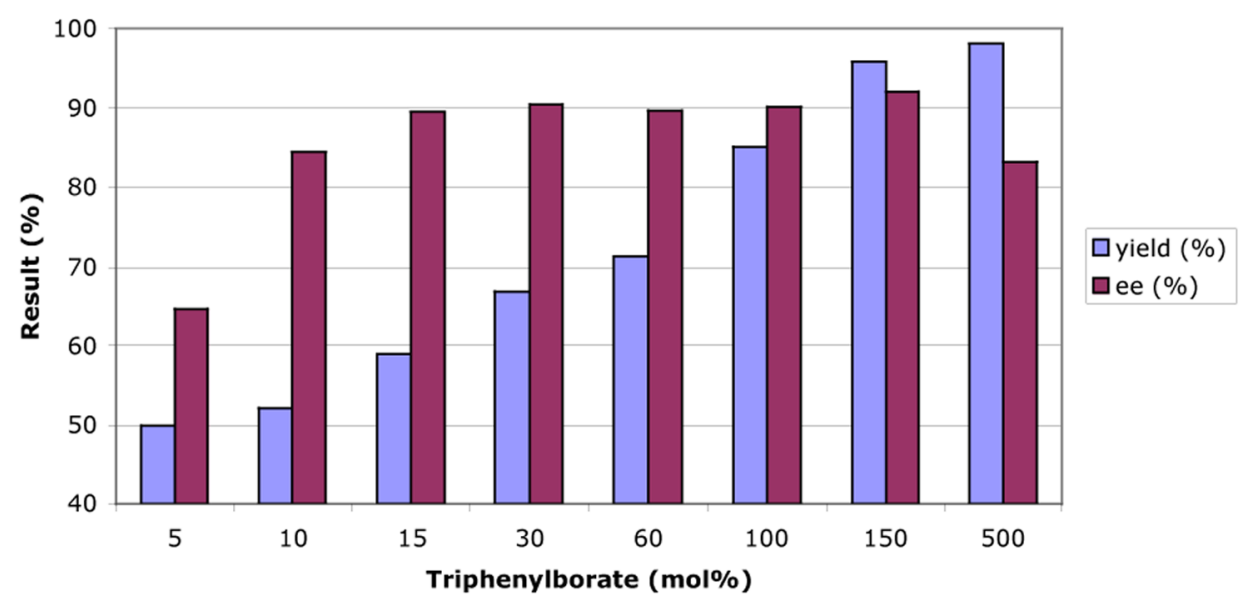

Chart. 1.

Effect of Triphenylborate Loading With 5 mol\% VAPOL 


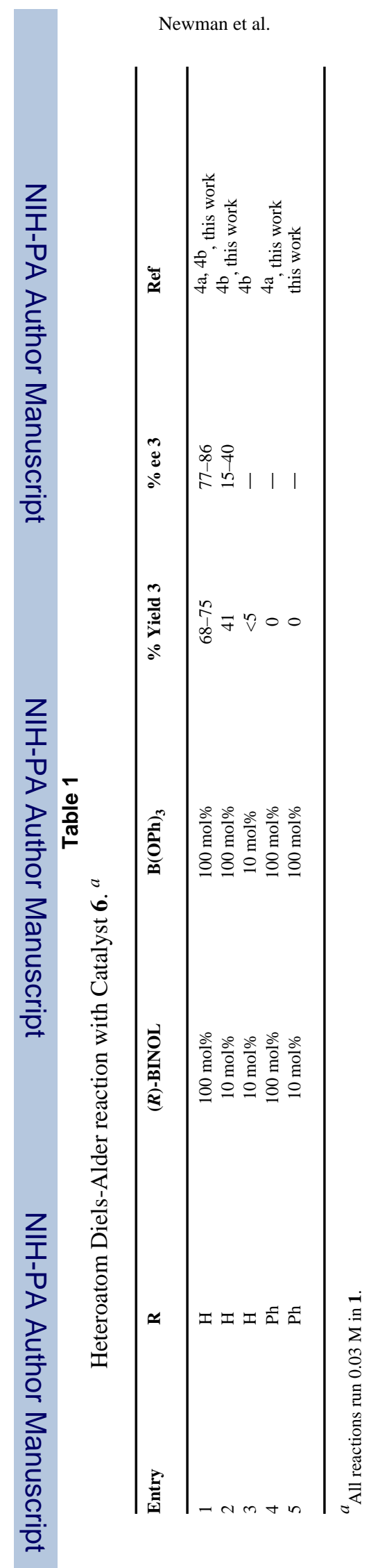

Page 6 


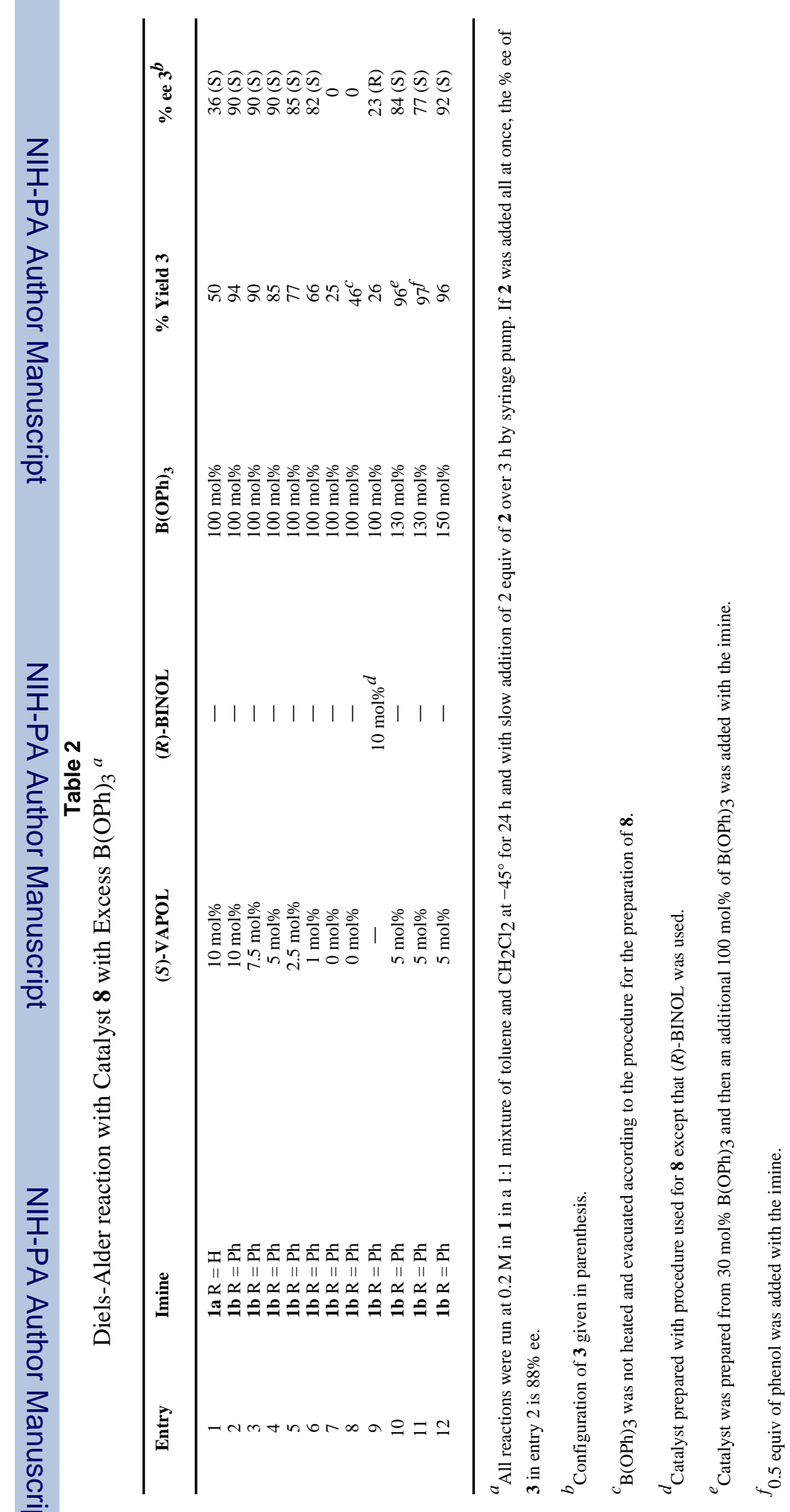

J Am Chem Soc. Author manuscript; available in PMC 2008 September 15. 


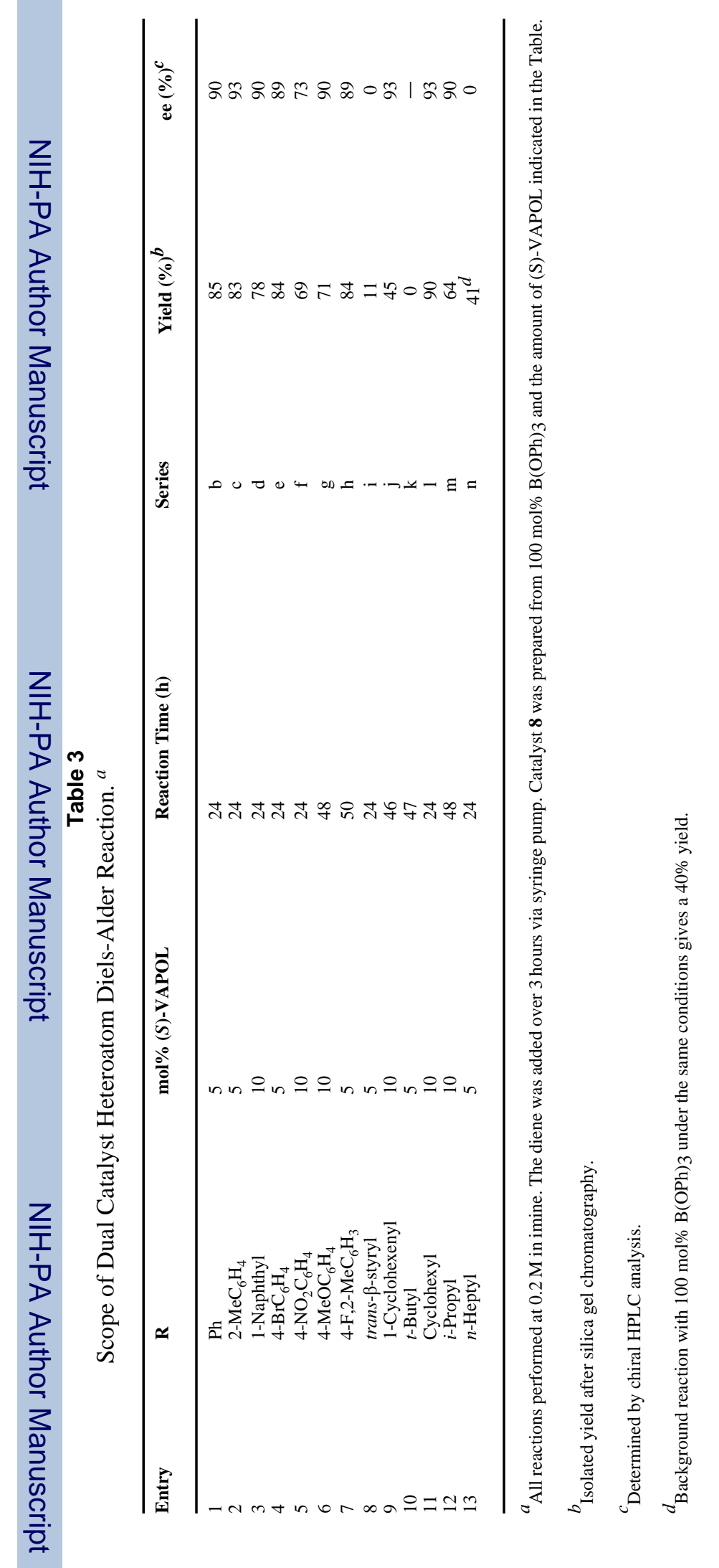

